\title{
Socioeconomic disparities in breast cancer survival: relation to stage at diagnosis, treatment and race Xue Qin $\mathrm{Yu}$
}

Address: Cancer Epidemiology Research Unit, Cancer Council New South Wales, PO Box 572, Kings Cross, NSW 1340, Australia Email: Xue Qin Yu - xueqiny@nswcc.org.au

Published: 14 October 2009

BMC Cancer 2009, 9:364 doi:10.1 |86/147|-2407-9-364
Received: 28 April 2009

Accepted: 14 October 2009

This article is available from: http://www.biomedcentral.com//47/-2407/9/364

(c) 2009 Yu; licensee BioMed Central Ltd.

This is an Open Access article distributed under the terms of the Creative Commons Attribution License (http://creativecommons.org/licenses/by/2.0), which permits unrestricted use, distribution, and reproduction in any medium, provided the original work is properly cited.

\begin{abstract}
Background: Previous studies have documented lower breast cancer survival among women with lower socioeconomic status (SES) in the United States. In this study, I examined the extent to which socioeconomic disparity in breast cancer survival was explained by stage at diagnosis, treatment, race and rural/urban residence using the Surveillance, Epidemiology, and End Results (SEER) data.

Methods: Women diagnosed with breast cancer during 1998-2002 in the I3 SEER cancer registry areas were followed-up to the end of 2005. The association between an area-based measure of SES and cause-specific five-year survival was estimated using Cox regression models. Six models were used to assess the extent to which SES differences in survival were explained by clinical and demographical factors. The base model estimated the hazard ratio (HR) by SES only and then additional adjustments were made sequentially for: 1) age and year of diagnosis; 2) stage at diagnosis; 3) first course treatment; 4) race; and 5) rural/urban residence.

Results: An inverse association was found between SES and risk of dying from breast cancer ( $p<$ $0.000 \mathrm{I})$. As area-level SES falls, HR rises $(\mathrm{I} .00 \rightarrow \mathrm{I} .05 \rightarrow \mathrm{I} .23 \rightarrow \mathrm{I} .3 \mathrm{I})$ with the two lowest SES groups having statistically higher HRs. This SES differential completely disappeared after full adjustment for clinical and demographical factors $(p=0.20)$.

Conclusion: Stage at diagnosis, first course treatment and race explained most of the socioeconomic disparity in breast cancer survival. Targeted interventions to increase breast cancer screening and treatment coverage in patients with lower SES could reduce much of socioeconomic disparity.
\end{abstract}

\section{Background}

Previous studies have documented substantial disparities in breast cancer survival in relation to socioeconomic status (SES) as measured either at the individual $[1,2]$ or area levels [3-6] in the United States, with women in lower SES groups showing poorer survival. Factors that may mediate these disparities include differences in the stage at diagnosis, access to and quality of care delivered and other correlates of low SES [7]. Women with less education and those who are unemployed, reside in a poor area, or are uninsured or under-insured are more likely to be diagnosed at later stages [8-10], and are less likely to receive optimal cancer care $[11,12]$. Race has been reported to be related with breast cancer survival independently of SES $[5,13]$.

Limitations of most prior US studies that have examined disparities in breast cancer survival by SES are that they considered only women with early stage diagnosis $[4,14$ - 
17] or those over age 65 years $[1,4,9,13,17-19]$. Other studies involved patients at a single institution $[2,14]$. Therefore, they may not be representative of the entire population diagnosed with breast cancer. In this study, I examined the extent to which these disparities was explained by stage at diagnosis, first course treatment, race and rural/urban residence by taking account of these variables, from the Surveillance, Epidemiology, and End Results (SEER) database, simultaneously and including all women diagnosed with breast cancer.

\section{Methods}

\section{Study population}

Women aged 15 years or older and diagnosed with first primary invasive breast cancer (ICDO-3 code: C50) [20] between January 1, 1998 and December 31, 2002 were identified through the 13 population-based cancer registries in the United States that participated in the SEER program (Atlanta, Connecticut, Detroit, Hawaii, Iowa, New Mexico, San Francisco-Oakland, Seattle-Puget Sound, Utah, Los Angeles, San Jose-Monterey, Rural Georgia and the Alaska Native Registry). Of the 113,905 women, a total of $1362(1.2 \%)$ cases were excluded from the analysis because they were diagnosed at autopsy or through death certificate only $(\mathrm{n}=705)$, had unknown race $(\mathrm{n}=$ $647)$ or missing residential address at diagnosis $(n=10)$.

\section{Study variables}

The outcome variable was survival time after diagnosis of breast cancer. The primary study variable was a composite measure of SES. As the SEER program does not collect individual level measures of SES, a composite variable was used based on two characteristics in county of residence: "percent of adults with $<12$ year education" and "percent of families living below the federal poverty line". Data were obtained from the 1990 U.S. Census. Educational level was categorized into 4 similar size groups $(1 \rightarrow 4$ from high to low) and poverty rate was divided into 3 major groups using the cutpoints: $\leq 9.9 \%$ (low), 10 $19.9 \%$ (medium), $\geq 20 \%$ (high) as recommended by others based on empirical research [21]. Counties were divided into four groups according to their levels of these two SES measures so that each group had similar number of cases. Counties with the educational level one (highest) and lowest poverty rate was categorized as high SES; counties with either educational level one and medium poverty rate, or lowest poverty rate and educational level two were assigned to the upper middle SES group; counties with educational level four and medium or high poverty rate, or educational level three and high poverty rate were classified as the lowest SES group; the remaining combination was the lower middle SES group. Women were allocated into each of the SES groups according to the county they lived in at diagnosis.
The following factors that may affect survival between SES groups were included in the analysis. Year of diagnosis were 1998 to 2002. Age at diagnosis was categorized into 5 groups: (15-44 years, 45-54 years, 55-64 years, 65-74 years and $>=75$ years). Race was categorized into three broad groups (White, Black and other). Rural/urban residence was defined based on the rural-urban continuum codes for 2003 available at http://seer.cancer.gov/seerstat/ variables/countyattribs/ruralurban.html. Women were categorized as living in an urban area if their county was located in a metro area (code 1, 2, 3 on the continuum codes). Stage at diagnosis, using American Joint Committee on Cancer (AJCC) stage [22], was categorized into 5 groups: stage I, II, III, IV and unknown stage or not applicable. Number of lymph nodes positive for those having lymph nodes examined was categorized into 3 groups: none, 1-3, and $\geq 4$ [23]. Information on the first course treatment (surgery and/or radiation) was dichotomized into receipt/no receipt categories. Detailed surgery definition from SEER data can be found from SEER website http://seer.cancer.gov/manuals/historic/AppendC.pdf.

Briefly, there are two types of surgeries: breast-conserving surgery and mastectomy. Breast-conserving surgery was defined as receiving segmental mastectomy, lumpectomy, nipple resection, excisional biopsy or partial mastectomy unspecified, and mastectomy included total, modified radical, radical, extended radical mastectomy or mastectomy unspecified. Chemotherapy, immunotherapy and hormonal therapy were not considered since they are not in the SEER public-use files.

\section{Statistical analysis}

The SEER data provide vital status and survival time for each patient, calculated in months using date of diagnosis and end of study, either date of death or the end of 2005 (the cut-off date of follow-up), whichever occurred first. Cause-specific survival was used for the hazard ratios (HR) estimation. A HR represents the risk of dying from breast cancer. Women were censored for death from causes other than breast cancer, or at the end of 2005.

In order to control for the effect of multiple factors simultaneously on disparities in breast cancer survival, the effect of SES on survival was estimated using Cox proportional hazard models. Briefly, these analyses consisted of six models. The basis model (model 0) estimated HR by SES without any adjustment using the highest SES group as a reference. Model 1 adjusted for age group at diagnosis and year of diagnosis. Ninety-five percent confidence intervals (CIs) for the HRs were calculated using the estimated coefficients and standard errors from the Cox regression models. A test of linear hypotheses about the effect of SES with p-value of $<0.05$ was considered to be statistically significant. 
In models two to five, HR for each SES group was estimated with additional adjustment for (2) AJCC stage and number of positive lymph nodes, (3) first course treatments, (4) race, (5) rural/urban residence at diagnosis, respectively. This was used to ascertain if adjustment for each group of factors reduced the survival difference between SES groups $[7,24]$. The validity of the proportional hazards of the predictors was tested by stratifying on the predictors and comparing the parameter estimates of the stratified model with those from the model including the variable as a proportional predictor $[25,26]$. No violations of proportionality of hazard were found. Patient data were obtained using the SEER software SEER*Stat version 6.4.4. All statistical analyses were performed using SAS 9.1 (SAS Institute, NC).

\section{Results}

A total of 112,543 women diagnosed with breast cancer were included in this analysis. Univariate analysis showed that all the variables listed in Table 1 were highly associ- ated with SES level based on area of residence at the time of diagnosis. As shown in Table 1, women living in the lowest SES areas had the lowest percentage of early stage (I): $41.4 \%$ vs $45.7-46.7 \%$, and highest percentage of advanced stages (III, IV): $13.0 \%$ vs $9.5-9.9 \%$ and were more likely to have $\geq 4$ lymph nodes positive: $16.0 \%$ vs $12.3-12.8 \%$. The proportion of Black women living in the lowest SES areas was nearly four times higher than that of the highest SES areas: $16.1 \%$ vs $4.3 \%$. The proportions of women from the two lowest SES areas who received the first course treatment were lower than that of the highest SES areas, especially for radiation ( $<48 \%$ vs $57.3 \%)$. The proportion living in rural areas for women from lower middle group was much higher than these of other groups $(23.1 \%$ vs $<4.0 \%)$.

Table 2 shows the results of Cox regression modelling with an inverse association between SES and risk of dying from breast cancer $(1.00 \rightarrow 1.05 \rightarrow 1.23 \rightarrow 1.31)$. When adjusting for age at diagnosis and calendar year (model

Table I: Distribution of study variables by socioeconomic status (SES), breast cancer diagnosed in 1998-2002

\begin{tabular}{|c|c|c|c|c|c|c|}
\hline & \multirow[b]{2}{*}{ Number of cases } & \multicolumn{4}{|c|}{ Percentage of area-based SES group } & \multirow[b]{2}{*}{ p-value } \\
\hline & & Highest SES & Upper middle & Lower middle & Lowest SES & \\
\hline \multicolumn{2}{|c|}{ Age at diagnosis (year) } & & & & & $<0.0001$ \\
\hline $15-44$ & 15520 & 14.4 & 14.0 & 12.4 & 14.4 & \\
\hline $45-54$ & 26545 & 25.2 & 23.3 & 22.3 & 23.6 & \\
\hline $55-64$ & 25545 & 23.3 & 23.2 & 21.9 & 22.5 & \\
\hline $65-74$ & 22462 & 18.6 & 19.7 & 21.1 & 20.3 & \\
\hline $75+$ & $2247 \mid$ & 18.4 & 19.8 & 22.3 & 19.2 & \\
\hline \multicolumn{2}{|c|}{ Year of diagnosis } & & & & & $<0.0001$ \\
\hline 1998 & 22134 & 19.4 & 18.4 & 21.4 & 19.4 & \\
\hline 1999 & 22487 & 19.5 & 18.7 & 21.3 & 20.1 & \\
\hline 2000 & 22385 & 20.2 & 21.0 & 18.6 & 20.0 & \\
\hline 2001 & 22791 & 20.3 & 20.9 & 19.6 & 20.2 & \\
\hline 2002 & 22746 & 20.6 & 21.0 & 19.1 & 20.3 & \\
\hline \multicolumn{2}{|l|}{ Race } & & & & & $<0.0001$ \\
\hline White & 92717 & 90.8 & 79.7 & 85.4 & 74.4 & \\
\hline Black & 9831 & 4.3 & 7.2 & 6.3 & 16.1 & \\
\hline Other & 9995 & 4.9 & 13.1 & 8.3 & 9.5 & \\
\hline \multicolumn{2}{|c|}{ Rural/urban residence } & & & & & $<0.0001$ \\
\hline Rural & 9819 & 2.7 & 4.0 & 23.1 & 4.0 & \\
\hline Urban & 102724 & 97.3 & 96.0 & 76.9 & 96.0 & \\
\hline \multicolumn{2}{|l|}{ AJCC' stage } & & & & & $<0.0001$ \\
\hline 1 & 50608 & 46.7 & 45.7 & 46.6 & 41.4 & \\
\hline II & 41646 & 36.2 & 37.1 & 35.1 & 39.5 & \\
\hline III & 7188 & 5.7 & 5.8 & 5.5 & 8.3 & \\
\hline IV & 4770 & 3.8 & 4.1 & 4.3 & 4.7 & \\
\hline Unknown & 8331 & 7.6 & 7.3 & 8.5 & 6.2 & \\
\hline \multicolumn{2}{|c|}{ Number of positive lymph nodes } & & & & & $<0.0001$ \\
\hline None & 60700 & 64.9 & 64.0 & 65.4 & 60.2 & \\
\hline $1-3$ & 21948 & 22.8 & 23.2 & 21.9 & 23.9 & \\
\hline$\geq 4$ & 12896 & 12.3 & 12.8 & 12.7 & 16.0 & \\
\hline \multicolumn{7}{|c|}{ First course treatment received } \\
\hline Surgery & 106076 & 95.3 & 94.5 & 93.6 & 93.8 & $<0.0001$ \\
\hline Radiation & $58 \mid 44$ & 57.3 & 55.1 & 47.8 & 47.7 & $<0.0001$ \\
\hline
\end{tabular}

† AJCC: American Joint Committee on Cancer. 
Table 2: Hazard ratio (HR) of cancer-specific mortality from breast cancer by socioeconomic status (SES)

\begin{tabular}{|c|c|c|c|c|c|c|}
\hline \multirow{3}{*}{$\begin{array}{l}\text { Area-based SES } \\
\text { group }\end{array}$} & Model 0 & Model I & Model 2 & Model 3 & Model 4 & Model 5 \\
\hline & SES only & $\begin{array}{c}\text { Model } 0+\text { age } \& \\
\text { year }\end{array}$ & Model I + stage & $\begin{array}{l}\text { Model } 2+ \\
\text { treatment }\end{array}$ & Model 3 + race & $\begin{array}{c}\text { Model } 4+\text { rural } / \\
\text { urban }\end{array}$ \\
\hline & HR \& $(\mathrm{Cl} \dagger)$ & $\mathrm{HR} \&(\mathrm{Cl})$ & $\mathrm{HR} \&(\mathrm{Cl})$ & HR \& (Cl) & HR \& (Cl) & HR \& (Cl) \\
\hline Highest & 1.00 & 1.00 & 1.00 & 1.00 & 1.00 & 1.00 \\
\hline Upper middle & $\begin{array}{c}1.05 \\
(0.99-1.11)\end{array}$ & $\begin{array}{c}1.01 \\
(0.96-1.07)\end{array}$ & $\begin{array}{c}1.00 \\
(0.94-1.06)\end{array}$ & $\begin{array}{c}1.00 \\
(0.95-1.06)\end{array}$ & $\begin{array}{c}0.99 \\
(0.93-1.05)\end{array}$ & $\begin{array}{c}0.99 \\
(0.93-1.05)\end{array}$ \\
\hline Lower middle & $\begin{array}{c}1.23 \\
(1.16-1.29)\end{array}$ & $\begin{array}{c}1.09 \\
(1.03-1.15)\end{array}$ & $\begin{array}{c}1.08 \\
(1.03-1.14)\end{array}$ & $\begin{array}{c}1.07 \\
(1.01-1.12)\end{array}$ & $\begin{array}{c}1.06 \\
(1.00-1.12)\end{array}$ & $\begin{array}{c}1.04 \\
(0.99-1.10)\end{array}$ \\
\hline Lowest & $\begin{array}{c}1.31 \\
(1.24-1.38)\end{array}$ & $\begin{array}{c}1.19 \\
(1.13-1.26)\end{array}$ & $\begin{array}{c}1.10 \\
(1.04-1.16)\end{array}$ & $\begin{array}{c}1.08 \\
(1.03-1.14)\end{array}$ & $\begin{array}{c}1.03 \\
(0.97-1.08)\end{array}$ & $\begin{array}{c}1.03 \\
(0.97-1.08)\end{array}$ \\
\hline $\mathrm{P}$-value for SES & $<0.0001$ & $<0.0001$ & $<0.0001$ & 0.003 & 0.07 & 0.20 \\
\hline
\end{tabular}

† $95 \%$ confidence intervals.

1), the HRs remained significantly higher for women residing in the two lowest SES areas; women from the lowest SES areas had $19 \%$ higher hazard of cancer-related death $(\mathrm{HR}=1.19)$ than women from the reference - highest SES group $(\mathrm{p}<0.0001)$. After additional adjustment for stage at diagnosis (model 2), the HR for the lowest SES group dropped to 1.10, but remained significant. Further adjustment for first course treatment (model 3) reduced the HRs for the lowest SES groups slightly $(1.10 \rightarrow 1.08)$. Then when adding race to the model (model 4 ), the HR for the lowest SES group was non-significant $(\mathrm{HR}=1.03$, 95\% CI: 0.97-1.08). Further, the overall effect of SES was reduced from highly significant $(\mathrm{p}<0.0001)$ in the base model to non-significant $(\mathrm{p}=0.07)$ in model 4 . Final adjustment for rural/urban residence (model 5 ) further weakened this SES differential $(p=0.20)$ with no SES group having significant higher HR than that of the top SES group.

Race-specific survivals were presented in Figure 1.

\section{Discussion}

An inverse association was found between SES and risk of dying from breast cancer among 112,543 breast cancer patients. More importantly, stepwise adjustment for stage at diagnosis, first course treatment, race and rural/urban residence completely eliminated the survival disparity associated with lower SES. The strength of this study is that it considered women of all ages diagnosed with any stage of breast cancer in SEER database and thus had much broader coverage and greater statistical power than previous studies of this issue.

A strength of this study is that the finding of a social association in breast cancer survival was not affected by choice of data source (17 or 13 SEER registries) or categories of SES (quintile or quartile, single or composite). This implies that the models are robust, and the effect of place of residence was probably real and not due to statistical artifact. These results were also consistent with many other studies examining SES disparities in breast cancer survival in the United States [1,3] and other parts of the world $[7,27]$. Further this study is population-based and includes all women diagnosed with breast cancer in the 13 SEER areas from 1998 to 2002 and followed-up until the most recent cut-off date - December 31, 2005. Therefore, these results potentially reflected experiences of the entire population diagnosed with breast cancer in the 13 SEER areas and provided a full picture of most recent socioeconomic disparity in breast cancer survival.

This analysis is limited by the allocation of cases to SES groups using aggregated data. It is possible that individual people may have been misclassified and the inferences at

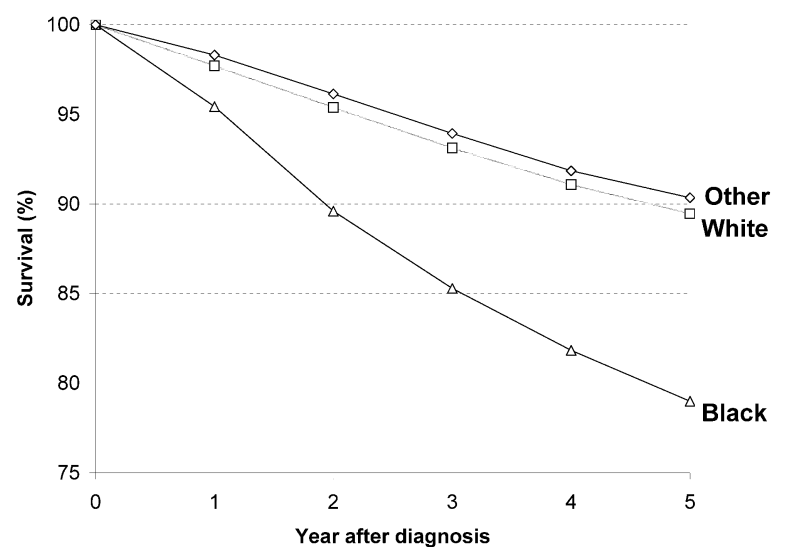

Figure I

Cause-specific survival from breast cancer diagnosed 1998-2002 followed-up to 2005 by race. 
the area level do not directly transfer to individuals. However, several studies have demonstrated the importance of area-based socioeconomic measures in measuring health inequality in the United States [28] and other parts of the world $[7,27]$. The second limitation of this study is the quality and completeness of treatment data in the SEER database: adjustment for the first course treatment (surgery and radiation) would not necessarily control for all dimensions of treatment for breast cancer, and in addition chemotherapy and hormonal therapy data are not available in the SEER public-use files. The data was also analyzed after categorizing receipt of treatment according to stage at diagnosis, surgery (mastectomy or breast conserving surgery) and radiation; and it was found that this grouping did not change the main findings.

Stage at diagnosis explained a large part of the SES disparity in breast cancer survival. This is likely because women living in the lowest SES areas had highest percent of advanced stages (III, IV) and $\geq 4$ lymph nodes positive (Table 1) and much worse survival for those with advanced stage disease. This unfavorable stage distribution for women from the lowest SES areas was likely caused by lower mammography rates. Lack of health insurance and lower financial resources are known to be associated with lower mammography rates $[8-10,29,30]$ and lack of, or delayed follow-up after an abnormal mammogram [31].

The contribution of first course treatment to the SES differential in breast cancer survival was rather small in this study because a large part of this differential had been captured by the differences in stage distribution between SES groups; those women diagnosed with later stage disease are more likely to receive inadequate treatment. However, possible explanations for women residing in lower SES areas for receiving inadequate care more often include lack of health insurance [14], comorbidities [32] and patients refusal or not adherence to therapies $[2,33]$, and provider bias $[11,34]$.

The gap in hazard of dying from breast cancer between the highest and lowest areas was reduced further and the overall effect of SES became non-significant $(\mathrm{p}=0.07)$ after additional adjustment for race (Table 2). This is in part because blacks were disproportionately represented in the lowest SES group $(16.1 \%$ ) (Table 1 ) and had lower survival rate (Figure 1). However, the contribution of race to the SES differential in breast cancer survival was modest because a substantial proportion of SES disparities associated with race may have been captured by differences in stage at diagnosis and treatment. Consistent with the wide literature $[3-5,13,18,19,33,35-39]$, the data indicated that black women were more likely to have later stages (III, IV) disease diagnosis $(17.1 \%$ vs $10.6 \%)$ and less likely to receive first course treatment - surgery $(90.3 \%$ vs $94.3 \%)$ and radiation ( $46.0 \%$ vs $51.7 \%$ ) than the general population (data not shown). In addition, black women are more likely to have unfavorable tumor characteristics negative hormone receptor status (ER/PR) or HER2-negative, higher-grade tumors and being diagnosed at younger age. Lower SES and inadequate access to medical care may interact with biological factors consequently leading to the disproportionate number of diagnoses of tumors with these unfavorable characteristics in younger black women. A more recent study found that black race was associated with increased mortality from breast cancer after adjusting for stage of disease and treatment, the authors therefore thought that biological or host genetic factors may be the potential source of the survival gap [40]. However, other studies reported that black women still had poorer outcomes from breast cancer after controlling for biological factors $[1,4,37]$. Overall, these data showed that race picks up some residual effect after controlling for measured variation in stage at diagnosis and first course treatment, which may be due to measurement errors, and some factors not related to these two variables, such as, biological characteristics. However, race is a complex and composite measure of many factors related with breast cancer survival and this study has limited ability to separate out these multiple dimensions of race that may influence survival.

There were some residual survival differentials between the highest and lower middle groups after adjusting for stage, first course treatment and race. This may be due to difference in the use of chemotherapy and/or hormonal therapy, which are not available in the SEER public-use data. Several studies found that women living in non-metropolitan areas in the U.S. were more likely to have delayed initiation of radiotherapy [32] and chemotherapy [17] after breast cancer surgery. The results of the HR for lower middle group becoming non-significant after further adjustment for rural/urban residence (Table 2), together with much more women in this group living in rural areas (Table 1), suggested that factors related to access to and/or time waiting for chemotherapy and/or radiotherapy may partly be attributable to the residual survival difference.

\section{Conclusion}

Stage at diagnosis, first course treatment and race explained most of the socioeconomic disparities in breast cancer survival. Thus, targeted interventions to increase breast cancer screening and treatment coverage in patients with lower SES could reduce much of socioeconomic disparity in breast cancer survival.

\section{List of abbreviations}

SEER: Surveillance, Epidemiology, and End Results; SES: socioeconomic status; AJCC: American Joint Committee on Cancer; HR: hazard ratio; CI: confidence intervals. 


\section{Competing interests}

The author declares that he has no competing interests.

\section{Authors' contributions}

I conceived the study, did the data analysis, drafted the manuscript, and approved the final version submitted for publication.

\section{Acknowledgements}

This study was completed while I was employed with the American Cancer Society. I thank Drs. Ahmedin Jemal and Michael Thun for providing comments and proofreading earlier drafts of this manuscript. I am supported by an Australian NHMRC Training Public Health fellowship (550002).

\section{References}

I. Bradley Cl, Given CW, Roberts C: Race, socioeconomic status, and breast cancer treatment and survival. J Natl Cancer Inst 2002, 94(7):490-496.

2. Kim SH, Ferrante J, Won BR, Hameed M: Barriers to adequate follow-up during adjuvant therapy may be important factors in the worse outcome for Black women after breast cancer treatment. World J Surg Oncol 2008, 6:26

3. Byers TE, Wolf HJ, Bauer KR, Bolick-Aldrich S, Chen VW, Finch JL, Fulton JP, Schymura MJ, Shen T, Van Heest S, et al.: The impact of socioeconomic status on survival after cancer in the United States: findings from the National Program of Cancer Registries Patterns of Care Study. Cancer 2008, I I 3(3):582-59 I.

4. Du XL, Fang S, Meyer TE: Impact of treatment and socioeconomic status on racial disparities in survival among older women with breast cancer. Am / Clin Oncol 2008, 3 I (2): | 25- I 32

5. Newman LA, Griffith KA, Jatoi I, Simon MS, Crowe JP, Colditz GA: Meta-analysis of survival in African American and white American patients with breast cancer: ethnicity compared with socioeconomic status. J Clin Oncol 2006, 24(9): I342-I349.

6. Ward E, Jemal A, Cokkinides V, Singh GK, Cardinez C, Ghafoor A Thun $M$ : Cancer disparities by race/ethnicity and socioeconomic status. CA Cancer J Clin 2004, 54(2):78-93.

7. Yu XQ, O'Connell DL, Gibberd RW, Armstrong BK: Assessing the impact of socio-economic status on cancer survival in New South Wales, Australia I 996-200 I. Cancer Causes Control 2008, I 9(10): 1383-1390.

8. MacKinnon JA, Duncan RC, Huang Y, Lee DJ, Fleming LE, Voti L, Rudolph M, Wilkinson JD: Detecting an association between socioeconomic status and late stage breast cancer using spatial analysis and area-based measures. Cancer Epidemiol Biomarkers Prev 2007, I 6(4):756-762.

9. Sabatino SA, Coates RJ, Uhler RJ, Breen N, Tangka F, Shaw KM: Disparities in mammography use among US women aged 40-64 years, by race, ethnicity, income, and health insurance status, 1993 and 2005. Med Care 2008, 46(7):692-700.

10. Ward E, Halpern M, Schrag N, Cokkinides V, DeSantis C, Bandi P, Siegel R, Stewart A, Jemal A: Association of insurance with cancer care utilization and outcomes. CA Cancer J Clin 2008 58(I):9-31.

II. Bickell NA, LePar F, Wang JJ, Leventhal H: Lost opportunities: physicians' reasons and disparities in breast cancer treatment. I Clin Oncol 2007, 25( I 8):25 I 6-252I.

12. Edwards BK, Brown ML, Wingo PA, Howe HL, Ward E, Ries LA, Schrag D, Jamison PM, Jemal A, Wu XC, et al.: Annual report to the nation on the status of cancer, $1975-2002$ featuring population-based trends in cancer treatment. J Natl Cancer Inst 2005, 97( I 9): | 407-| 427.

13. Curtis E, Quale C, Haggstrom D, Smith-Bindman R: Racial and ethnic differences in breast cancer survival: how much is explained by screening, tumor severity, biology, treatment, comorbidities, and demographics? Cancer 2008, I I 2(I): |7|-|80.

14. Bickell NA, Cohen A: Understanding reasons for underuse: an approach to improve quality and reduce disparities in breast cancer treatment. Mt Sinai J Med 2008, 75(I):23-30.
I5. Bilimoria KY, Bentrem DJ, Feinglass JM, Stewart AK, Winchester DP, Talamonti MS, Ko CY: Directing surgical quality improvement initiatives: comparison of perioperative mortality and longterm survival for cancer surgery. I Clin Oncol 2008, 26(28):4626-4633.

16. Esnaola NF, Knott K, Finney C, Gebregziabher M, Ford ME: Urban/ rural residence moderates effect of race on receipt of surgery in patients with nonmetastatic breast cancer: a report from the South Carolina central cancer registry. Ann Surg Oncol 2008, I 5(7): 1828-1836.

17. Hershman DL, Wang X, McBride R, Jacobson JS, Grann VR, Neugut $\mathrm{Al}$ : Delay of adjuvant chemotherapy initiation following breast cancer surgery among elderly women. Breast Cancer Res Treat 2006, 99(3):313-321.

18. Gross CP, Smith BD, Wolf E, Andersen M: Racial disparities in cancer therapy: did the gap narrow between 1992 and 2002 ? Cancer 2008, I I 2(4):900-908.

19. Haas JS, Earle CC, Orav JE, Brawarsky P, Keohane M, Neville BA, Williams DR: Racial segregation and disparities in breast cancer care and mortality. Cancer 2008, I I 3(8):2 I66-2I72.

20. Fritz A, Percy C, Jack A, Shanmugaratnam K, Sobin L, Parkin D, Whelan S, eds: International Classification of Diseases for Oncology. 3rd edition. Geneva, Switzerland: World Health Organisation; 2000

21. Singh GK, Miller B, Hankey B, Edwards BK: Area socioeconomic variation in U.S. cancer incidence, mortality, stage, treatment, and survival, 1975-1999. Bethesda: MD: National Cancer Institute; 2003.

22. Greene F, Page D, Fleming I, Fritz A, Balch C, Haller D, Morrow M, eds: AJCC Cancer Staging Manual. 6th edition. Philadelphia: Springer; 2002.

23. Truong PT, Vinh-Hung V, Cserni G, Woodward WA, Tai P, Vlastos $G$ : The number of positive nodes and the ratio of positive to excised nodes are significant predictors of survival in women with micrometastatic node-positive breast cancer. Eur J Cancer 2008, 44(1 2): 1670-1677.

24. Yu XQ, O'Connell DL, Gibberd RW, Smith DP, Dickman PW, Armstrong BK: Estimating regional variation in cancer survival: a tool for improving cancer care. Cancer Causes Control 2004 I5(6):6| |-6|8.

25. Bradburn MJ, Clark TG, Love SB, Altman DG: Survival analysis Part III: multivariate data analysis -- choosing a model and assessing its adequacy and fit. $\mathrm{Br} /$ Cancer 2003, 89(4):605-6I I.

26. UCLA: Academic Technology Services, Statistical Consulting Group [http://www.ats.ucla.edu/stat/sas/seminars/sas survival/]

27. Woods LM, Rachet B, Coleman MP: Origins of socio-economic inequalities in cancer survival: a review. Ann Oncol 2006, I7(I):5-19.

28. Krieger N, Chen JT, Waterman PD, Soobader MJ, Subramanian SV, Carson R: Geocoding and monitoring of US socioeconomic inequalities in mortality and cancer incidence: does the choice of area-based measure and geographic level matter?: the Public Health Disparities Geocoding Project. Am J Epidemiol 2002, I 56(5):47I-482

29. Robinson JM, Shavers V: The role of health insurance coverage in cancer screening utilization. I Health Care Poor Underserved 2008, I9(3):842-856

30. Schootman M, Walker MS, Jeffe DB, Rohrer JE, Baker EA: Breast cancer screening and incidence in communities with a high proportion of uninsured. Am J Prev Med 2007, 33(5):379-386.

31. Yabroff KR, Breen N, Vernon SW, Meissner HI, Freedman AN, Ballard-Barbash $\mathrm{R}$ : What factors are associated with diagnostic follow-up after abnormal mammograms? Findings from a U.S. National Survey. Cancer Epidemiol Biomarkers Prev 2004, I3(5):723-732

32. Hershman DL, Wang X, McBride R, Jacobson JS, Grann VR, Neugut $\mathrm{Al}$ : Delay in initiating adjuvant radiotherapy following breast conservation surgery and its impact on survival. Int J Radiat Oncol Biol Phys 2006, 65(5): I 353-I360.

33. Bickell NA, Wang J, Oluwole S, Schrag D, Godfrey H, Hiotis K, Mendez J, Guth AA: Missed opportunities: racial disparities in adjuvant breast cancer treatment. I Clin Oncol 2006, 24(9): | $357-1362$.

34. Hershman DL, Buono D, McBride RB, Tsai WY, Joseph KA, Grann VR, Jacobson JS: Surgeon characteristics and receipt of adju- 
vant radiotherapy in women with breast cancer. J Natl Cancer Inst 2008, 100(3):199-206.

35. Bach PB, Pham HH, Schrag D, Tate RC, Hargraves JL: Primary care physicians who treat blacks and whites. N Engl J Med 2004, 35 I (6):575-584.

36. Baquet CR, Mishra SI, Commiskey P, Ellison GL, DeShields M: Breast cancer epidemiology in blacks and whites: disparities in incidence, mortality, survival rates and histology. I Natl Med Assoc 2008, 100(5):480-488.

37. Chu KC, Lamar CA, Freeman HP: Racial disparities in breast carcinoma survival rates: seperating factors that affect diagnosis from factors that affect treatment. Cancer 2003, 97(I I):2853-2860.

38. Lucas FL, Stukel TA, Morris AM, Siewers AE, Birkmeyer JD: Race and surgical mortality in the United States. Ann Surg 2006, 243(2):28I-286.

39. Srokowski TP, Fang S, Duan Z, Buchholz TA, Hortobagyi GN, Goodwin JS, Giordano SH: Completion of adjuvant radiation therapy among women with breast cancer. Cancer 2008, I I3(I):22-29.

40. Albain KS, Unger JM, Crowley JJ, Coltman CA Jr, Hershman DL: Racial Disparities in Cancer Survival Among Randomized Clinical Trials Patients of the Southwest Oncology Group. J Natl Cancer Inst 2009, I OI(14):984-992.

\section{Pre-publication history}

The pre-publication history for this paper can be accessed here:

http://www.biomedcentral.com/1471-2407/9/364/pre pub

Publish with Bio Med Central and every scientist can read your work free of charge

"BioMed Central will be the most significant development for disseminating the results of biomedical research in our lifetime. "

Sir Paul Nurse, Cancer Research UK

Your research papers will be:

- available free of charge to the entire biomedical community

- peer reviewed and published immediately upon acceptance

- cited in PubMed and archived on PubMed Central

- yours - you keep the copyright

Submit your manuscript here:

http://www.biomedcentral.com/info/publishing_adv.asp 